\title{
Analysis on the influencing factors of industrial structure upgrading in Northeast China
}

\author{
Dapeng Dong ${ }^{1, *}$, Yan $\mathrm{Xu}^{1}$, Guiyan Zhao ${ }^{2}$, and Yihui Qi ${ }^{1}$ \\ ${ }^{1}$ Heilongjiang Bayi Agricultural University,163319 Daqing, China \\ ${ }^{2}$ Fujian Polytechnic Normal University,350300, Fuqing, China
}

\begin{abstract}
Based on the panel data of 34 cities in Northeast China, this paper uses fixed-effect model and quantile regression method to empirically test the influencing factors of industrial structure upgrading. The results show that the government has led the upgrading of the industrial structure in Northeast China, economic growth and investment in fixed assets has inhibitory effect on industrial structure upgrade, the level of opening to the outside world, the financial sector development and the increase of human capital in the northeast has obvious role in promoting industrial structure upgrade. The quantile regression results show that the coefficient of each factor are basically consistent with the estimated results of ordinary panel fixed effect model, which further verifies the robustness of the research conclusions in this paper.
\end{abstract}

\section{Introduction}

Northeast China is a typical region affected by the strategy of priority development of heavy industry. Relying on its resource advantages and prioritizing the development of heavy industry, it took the lead to build an industrial system dominated by heavy and chemical industries and became China's most important industrial base before the 1990s. However, with the deepening of the reform and the improvement of the market economy, the pace of industrial structure adjustment in favor of resource-based industries and heavy chemical industries is slow, the proportion of the original industrial system is too large, the development of emerging industries is insufficient, and the structural contradictions are prominent in the northeast of the old industrial base rapid decline. The revitalization strategy of the old industrial base in Northeast China has brought a decade of economic prosperity to the economic development of Northeast China. However, since 2014, the economic growth rate in Northeast China has dropped rapidly, which has aroused wide attention[1]. The formation and evolution of the industrial structure depends on regional resource endowments and institutional changes. There are obvious differences in factor endowments and institutional environments among different regions in China. The empirical research conclusions drawn from national research samples may not be applicable to specific regions. The formation and evolution of the industrial structure in the Northeast region is deeply influenced by the priority development strategy of heavy industry. Compared with other regions in China, it has obvious regional characteristics. The analysis of the Northeast region in this article is an extension of existing research. Based on this, this article uses panel data from
34 cities in the Northeast to explore the impact of various factors on the upgrading of the industrial structure under the strategy of revitalizing the old industrial base in Northeast China. This is very important for promoting the optimization of the economic structure in Northeast China and improving the quality of revitalization of the old industrial base.

\section{Model constrcution}

\subsection{Explained variables}

Upgrading of industrial structure (ind): Generally, industrial structure can be measured by selecting the proportion of non-agricultural industries based on Clark's theorem. However, due to the tremendous impact of the information technology revolution on the industrial structure, the economic structure of developed countries has a trend of priority development of the service industry, and the traditional measurement of industrial structure can no longer reflect the tendency of economic structure. In view of the fact that the tertiary industry develops significantly faster than the secondary industry, the ratio of the output value of the tertiary industry to the output value of the secondary industry is used as a measure of the industrial structure upgrade to show whether the industrial structure of the Northeast region is upgrading in the direction of "service-oriented" [2].

\subsection{Explanatory variables}

Government-led (gov) is measured by the proportion of local government fiscal expenditures to regional GDP to reflect the local government's ability to control resource

\footnotetext{
*Corresponding author: 64719202@qq.com
} 
allocation and the degree of participation in local economic development [3].

Regional economic growth (grow) is measured by the per capita GDP and take the logarithm of it.

Trade opening (open) is measured by the ratio of the total import and export of goods in the region and the region's GDP.

Development of financial industry (fis) is measured by the ratio of the loan of financial institutions to the gross regional product at the end of the year.

Human capital (edu) is measured by the proportion of the number of students in universities in the total population.

Fixed asset investment (inv) is measured by the proportion of fixed asset investment in GDP.

The scope of this study includes 34 cities in Liaoning Province, Jilin Province and Heilongjiang Province, and the sample data interval is set to 2003-2016.

Table 1. Descriptive statistics of related variables

\begin{tabular}{|c|c|c|c|c|c|}
\hline Variables & $\mathrm{N}$ & Mean & Std & Min & Max \\
\hline ind & 476 & 0.9327 & 0.4643 & 0.1286 & 2.9395 \\
\hline gov & 476 & 0.1629 & 0.0744 & 0.0312 & 0.5809 \\
\hline grow & 476 & 10.1467 & 0.7212 & 8.1798 & 11.9033 \\
\hline open & 476 & 0.1457 & 0.2197 & 0.0006 & 1.4229 \\
\hline fis & 476 & 0.7836 & 0.3464 & 0.1122 & 2.2662 \\
\hline inv & 476 & 0.5628 & 0.2378 & 0.1171 & 1.2638 \\
\hline edu & 476 & 0.0125 & 0.0142 & 0.0000 & 0.0690 \\
\hline
\end{tabular}

\subsection{Model setting}

In order to study the influence of the above factors on the upgrading of industrial structure, this paper constructs the following econometric model:

$$
\text { ind }_{i t}=\alpha_{i}+\sum_{j=1} \lambda_{j} x_{i j t}+\varepsilon_{i t}
$$

ind $_{i t}$ represents the industrial structure upgrade of the explained variable, and $x_{i j t}$ is a set of explanatory variables, including the government-led, regional economic growth, trade opening, financial industry development, human capital, and fixed capital investment selected above. $\lambda$ is the parameter to be estimated. For the above econometric model, the panel data fixed effect and random effect model methods are used to estimate the model parameters.

\section{Model estimation results}

\subsection{Regression results}

In this paper, panel fixed effect and random effect models were selected respectively for parameter estimation, and the estimation results are listed in Table 2. The parameter estimation results show that the influence coefficient of government-led behavior on the upgrading of industrial structure is significantly positive, that is, the strengthening of government's leading power in economic activities has a significant promoting effect on the upgrading of industrial structure in Northeast
China. There are many reasons for the decline of the Northeast economy and the "new Northeast phenomenon". The deep-seated reason is that the rigid, solidified, and low-level industrial structure has not been adjusted for a long time. During the implementation of the strategy for the revitalization of the old Northeast industrial base under the leadership of the government, the central government Developed scientific and clear industrial revitalization policies with provincial and local government departments established specific industrial structure transformation and upgrading goals. Local governments implemented relevant industrial revitalization policies through public financial expenditures and adjusted the allocation of production factors among the three industrial sectors, thereby promoting the upgrading of the industrial structure in the Northeast. The coefficient of economic growth and fixed assets investment is negative, has inhibitory effect on industrial structure upgrade. The reason is that the local government pays special attention to the economic growth ranking of the region, and then invests social and economic resources in the traditional advantageous industrial sectors with higher production efficiency and stronger growth effect, which has led to the suppression of the service-oriented transformation and upgrading of the industrial structure. Fixed asset investment has a tendency to invest more in the state-owned economy and capital-intensive industries, which is not conducive to the upgrading of the industrial structure in the Northeast. The level of opening to the outside world and the financial industry development and the increase of human capital has obvious role in promoting the upgrading of industrial structure in northeast China. To a certain extent, financial development can correct the tendency of Northeast China's financial resources to favor state-owned heavy chemical industries, and effectively play its role in optimizing resource allocation, thereby promoting the upgrading of the industrial structure in Northeast China. As a key input element of technological innovation, human capital has played an active role in promoting industrial transformation and upgrading in Northeast China. At the same time, foreign trade also has a certain positive effect on the upgrading of the industrial structure in the Northeast. This is also consistent with the research conclusions of the relevant literature, and in line with the theoretical expectations[4$6]$.

In addition, the number of resource-based cities in northeast China is large, the distribution is wide and the historical contribution is outstanding. Therefore, the cities involved in the study are divided into two categories: resource-based cities and non-resource-based cities. Among them, the resource-based cities include Fuxin, Songyuan, Daqing and other 19 cities, and the non-resource-based cities include Shenyang, Dalian, Changchun, Harbin and other 15 cities. Models (3) - (6) report the estimation results of fixed effect and random effect models for resource-based cities and non-resourcebased cities. The Hausman test statistics are 15.6 and 11.56 respectively, and the corresponding $\mathrm{P}$ values are 0.0161 and 0.0726 respectively. Therefore, the fixed effect model is more suitable. The estimated results of 
fixed effect models (3) and (5) are basically consistent with the overall estimated results of Northeast China, which also indicates that the research conclusions in this paper are robust.

Table 2. Regression results of panel data

\begin{tabular}{|c|c|c|c|c|c|c|}
\hline \multirow{2}{*}{} & \multicolumn{2}{|c|}{ Northeast China } & \multicolumn{2}{c|}{ resource-based cities } & \multicolumn{2}{c|}{ non-resource-based cities } \\
\cline { 2 - 7 } & FE (1) & RE $(2)$ & FE $(3)$ & RE $(4)$ & FE $(5)$ & RE $(6)$ \\
\hline \multirow{2}{*}{ gov } & $1.9768^{* * *}$ & $2.1687^{* * *}$ & $2.1722^{* * *}$ & $2.2721^{* * *}$ & $1.2232^{* * *}$ & $1.5723^{* * *}$ \\
& $(0.2191)$ & $(0.2138)$ & $(0.2601)$ & $(0.2560)$ & $(0.3892)$ & $(0.3755)$ \\
\hline \multirow{2}{*}{ grow } & -0.0444 & $-0.0584^{* *}$ & -0.0327 & -0.0411 & -0.0554 & -0.0674 \\
& $(0.0271)$ & $(0.0262)$ & $(0.0351)$ & $(0.0340)$ & $(0.0433)$ & $(0.0427)$ \\
\hline \multirow{2}{*}{ open } & 0.1184 & $0.1440^{*}$ & $0.1506^{*}$ & $0.2048^{* *}$ & 0.1841 & 0.0264 \\
& $(0.0773)$ & $(0.0749)$ & $(0.0824)$ & $(0.0817)$ & $(0.1940)$ & $(0.1729)$ \\
\hline \multirow{2}{*}{ fis } & $0.2905^{* * *}$ & $0.2747^{* * *}$ & $0.3521^{* * *}$ & $0.3479^{* * *}$ & $0.2659^{* * *}$ & $0.2315^{* * *}$ \\
& $(0.0428)$ & $(0.0428)$ & $(0.0591)$ & $(0.0592)$ & $(0.0610)$ & $(0.0602)$ \\
\hline \multirow{2}{*}{ inv } & $-0.4717^{* * *}$ & $-0.4601^{* * *}$ & $-0.3700^{* * *}$ & $-0.3469^{* * *}$ & $-0.5621^{* * *}$ & $-0.5780^{* * *}$ \\
& $(0.0610)$ & $(0.0606)$ & $(0.0765)$ & $(0.0760)$ & $(0.0956)$ & $(0.0957)$ \\
\hline \multirow{2}{*}{ edu } & $10.4793^{* * *}$ & $8.9942^{* * *}$ & $13.9908^{* * *}$ & $12.2655^{* * *}$ & $13.2399^{* * *}$ & $10.3670^{* * *}$ \\
& $(2.8359)$ & $(2.3716)$ & $(5.0840)$ & $(4.6240)$ & $(3.5298)$ & $(3.0461)$ \\
\hline \multirow{2}{*}{$\mathrm{C}$} & $0.9511^{* * *}$ & $1.0823^{* * *}$ & $0.6580^{* *}$ & $0.7235^{* *}$ & $1.2073^{* * *}$ & $1.3923^{* * *}$ \\
& $(0.2430)$ & $(0.2412)$ & $(0.3214)$ & $(0.3203)$ & $(0.3796)$ & $(0.3784)$ \\
\hline Hausman-p & \multicolumn{2}{|c|}{0.0006} & \multicolumn{3}{c}{0.0161} & \multicolumn{2}{c|}{0.0726} \\
\hline $\mathrm{N}$ & 476 & 476 & 266 & 266 & 210 & 210 \\
\hline
\end{tabular}

Note: The parentheses are standard errors. ${ }^{* * *},{ }^{* *}$ and $*$ indicate that the estimated coefficient is significant at the levels of $1 \%, 5 \%$ and $10 \%$ respectively.

\subsection{Quantile regression estimation of panel data}

The ordinary panel estimation model is a regression of the mean value, which mainly reflects the influence of explanatory variables on the conditional expectation of the explained variables. Therefore, the objective results at different levels cannot be investigated, so the reflected information is limited. Koenker and Basett (1978) proposed that "quantile regression" that can provide comprehensive information of conditional distribution, so as to more truly reflect the relationship between explanatory variables and explained variables, and make regression estimation results more accurate and detailed. Therefore, this paper selects $10 \%, 25 \%, 50 \%, 75 \%$ and $90 \%$ for regression estimation, so as to understand the influence of various factors on the upgrading of industrial structure under different conditional quantiles of industrial structure. It can be seen from the estimated results in Table 3 that, under all quantile conditions, the coefficient symbols of each factor are basically consistent with the estimated results of the ordinary panel fixed effect model, which further verifies the robustness of the research conclusions in this paper.

Table 3. Quantile regression estimation results of panel data

\begin{tabular}{|c|c|c|c|c|c|}
\hline & QR_10 & QR_25 & QR_50 & QR_75 & QR 90 \\
\hline \multirow{2}{*}{ gov } & $1.5469^{* * *}$ & $2.1387^{* * *}$ & $\begin{array}{c}2.5834^{* * *} \\
(0.6458)\end{array}$ & $\begin{array}{c}3.3190^{* * *} \\
(0.4825)\end{array}$ & $\begin{array}{c}3.7310^{* * *} \\
(1.0986)\end{array}$ \\
\hline \multirow{2}{*}{ grow } & $-0.1780^{* *}$ & $-0.1496^{* * *}$ & $-0.1664^{* * *}$ & $-0.1689^{* *}$ & $-0.1843^{*}$ \\
& $(0.0738)$ & $(0.0549)$ & $(0.0644)$ & $(0.0894)$ & $(0.1073)$ \\
\hline \multirow{2}{*}{ open } & $0.5394^{* * *}$ & $0.4717^{* *}$ & 0.3417 & 0.5433 & 0.7362 \\
& $(0.1765)$ & $(0.2359)$ & $(0.2935)$ & $(0.3647)$ & $(0.4791)$ \\
\hline \multirow{2}{*}{ fis } & $0.2177^{*}$ & 0.1397 & $0.1296^{*}$ & 0.0166 & $0.2958^{*}$ \\
& $(0.1278)$ & $(0.1357)$ & $(0.1199)$ & $0.1363)$ & $(0.1673)$ \\
\hline \multirow{2}{*}{ inv } & 0.1186 & -0.0878 & -0.1887 & $-0.5394 *$ & $-0.6516^{* *}$ \\
& $(0.1194)$ & $(0.1345)$ & $(0.1645)$ & $(0.2108)$ & $(0.2645)$ \\
\hline \multirow{2}{*}{ edu } & 6.6373 & 7.9652 & $11.8492^{* * *}$ & $13.0705^{* * *}$ & $9.0764^{* *}$ \\
& $(4.9373)$ & $(4.0361)$ & $(3.9436)$ & $(3.9886)$ & $(4.5929)$ \\
\hline \multirow{2}{*}{$\mathrm{C}$} & $1.5791 * *$ & $1.4944^{* * *}$ & $1.7910^{* * *}$ & $2.1482^{* * *}$ & $2.4251^{* *}$ \\
& $(0.7163)$ & $(0.5516)$ & $(0.5854)$ & $(0.8156)$ & $(1.0457)$ \\
\hline $\mathrm{N}$ & 476 & 476 & 476 & 476 & 476 \\
\hline
\end{tabular}

Note: The parentheses are standard errors. ${ }^{* *}, * *$ and $*$ indicate that the estimated coefficient is significant at the levels of $1 \%, 5 \%$ and $10 \%$ respectively.

\section{Research conclusions and policy recommendations}

The imbalance of the industrial structure dominated by heavy and chemical industry and the relatively slow process of marketization increase the vulnerability of the comprehensive revitalization of northeast China and weaken the potential of the future economic growth of northeast China. Based on the fact of industrial structure transformation and upgrading under the revitalization strategy of the old industrial base in Northeast China, 
this paper uses the data of 34 cities in Northeast China to empirically test the influencing factors of industrial structure upgrading by using fixed effect model and quantile regression method. The fixed effects regression results show that the government has led the upgrading of the industrial structure in Northeast China, economic growth and investment in fixed assets has inhibitory effect on industrial structure upgrade, the level of opening to the outside world, the financial sector development and the increase of human capital in the northeast has obvious role in promoting industrial structure upgrade. The regional heterogeneity analysis of resource-based cities and non-resource-based cities shows that there is no significant difference in the influence of relevant factors on the transformation and upgrading of industrial structure. The quantile regression results of panel data show that under all quantile conditions, the coefficient signs of each factor are basically consistent with the estimated results of panel fixed effect model, which further verifies the robustness of the research conclusions in this paper.

Based on the above research conclusions, this paper puts forward the following policy recommendations: First, governments should formulate scientific and reasonable industrial development policies based on the actual conditions of regional development, effectively guide the optimal allocation of resources, and promote the transformation and upgrading of the industrial structure. Second, for the reality of the lack of talent in Northeast China, the policy of talent training should be formulated to improve the level of human capital matching with industrial structure upgrading. Third, Northeast China should actively integrate into the "One Belt and One Road", expand the level of opening to the outside world, introduce high-quality resources and advanced technology to promote the upgrading of industrial structure, and promote the northeast superior products and technology to go out, and adjust the industrial structure flexibly with foreign trade. Fourth, Northeast China should improve the financial development environment, optimize the structure of financial development, enhance the efficiency of financial resource allocation, and provide financial support for the transformation and upgrading of industrial structure.

\section{Acknowledgements}

Planning Project of Philosophy and Social Science in Heilongjiang Province" Research on the Industrial Structure Transformation and Upgrading of Resourcebased Cities in the Northeast China under the Constraints of Environmental Regulations" (No.20JYE271).

\section{References}

1. Min C, Jiafeng Z. ZGRK7, 1 (2018)

2. Chunhui G, et al. JJYJ2, 5(2011)

3. Xinzhou F, Zili H. STUD6, 11(2015)

4. Enyi S, Na W. nkes1, 6(2018)
5. Lizhen L, Qinglong W. SHZX8, 2(2017)

6. $\mathrm{Hu}$ Z, Sinan D. JLJH3, 2(2017) 